\title{
Project Management as a Discipline in Africa
}

\author{
Benias Mapepeta ${ }^{1}$ \\ Project Management Zimbabwe (PMZ), PhD - Project Management (Prospective Student with Cranefield College)
}

\begin{abstract}
Project Management, while having been regarded as a simple song by most professionals in Africa, has been found wanting in terms of its footing as a discipline in the African continent. Of late, most professionals have been hitch-hiking into Project Management as a field of study from their original academic backgrounds. On its related literature, this Paper is going to look at various opinions which have been viewed in project management and regarded as factual researches while being unconventional researches based on business conferences and business deals exchanges of information. This paper is going to elaborate the importance of conventional fact finding based researches and how crucial they are in establishing a properly constituent field of study in Project Management. It is also going to highlight how effective and non effective(on Project Management), the current short-term courses and offered programmes as well as Post Graduate Diplomas being offered all around in Africa by African Institutes. The creation of professional ethical confusion on academic capabilities and technical application of experience in Project Management and its contribution to percentages of successes and failures of projects on the ground.Conclusively, the paper is going to run through possible recommendations on the way forward in trying to establish Project Management as a field of Study in Africa and the contribution to projects success in the continent.
\end{abstract}

Keywords: Academic qualification, Professional qualifications, Project, Project failure, Project Success

\section{INTRODUCTION}

Project Management has been there since the creation of the Earth. It is arguable that, as a field and or science, project management dates back to human creation. However, the conventional project management that we refer to today can be traced back to the origins of Engineering fields of study which has seen the field of project management growing in popularity in a few centuries ago.

Mounir (2013) postulates that, today, project management has spread to almost all fields and industries in the whole world. Such sectors includes the non-profit, health care, oil, gas, information, communication technology, pharmaceuticals, marketing, education, human resources just to mention but a few. This has contributed to the increased value of project management in modern organisations across all industries and business sectors. Specifically, project management can be classified into two segments, that is, the project management dating a few decades ago and modern project management which emerged in the middle of the twentieth century in the defense industries and major infrastructure projects, that is the engineering and construction industries.

\section{BACKGROUND TO THE STUDY}

According to Mounir (2013) project management increased its dominance in all sectors by the turn of the twentieth century which has seen a huge interest from many academics including professionals who started seeking certification in this field. With much generated interest, many professionals jumped guns from their fields of study to join the band wagon of modern project management.

Virtually, most successful organisations aligned themselves with this new concept of project management putting the field into spotlight attracting almost all professionals interested in success of their organisations. This created a fortune for some training institutes and a problem for the field of study.

Rwelamila (2012) argues that, "while project management is now being recognized as a means to achieve competitive advantage in Africa, project management still remains a Cinderella field". Meaning that many has to be learnt pertaining to project management as a field rather it is still a mythic story to both practitioners and beneficiaries alike.

It is with this background that this paper tries to highlight the importance of professionalising and academicising project management so that it can be recognized as a proper field of study in Africa.

${ }^{1}$ Corresponding Author: mapepeta@gmail.com 


\section{Statement OF THE Problem}

Harris (2014) argues that as much as project management has been a flower to bees and insects alike, it is imperative to note that up until a few years ago, no university in the whole world was offering project management as a field of study or as an independent educational domain. Mounir (2013) argues that, "even today, project management education is limited to a number of universities and mostly at the postgraduate level. Project Management education is still rare in colleges and or non-existent as an undergraduate field of study". He went on further to say that " consequently, to learn project management, professionals often rely on the literature from notfor-profit professional associations, alternatively they learn on the job."

However, according to Meyer (2013) project management as a growing field, there are lots of problems associated with growth. For one, is the damage to the image of an emerging profession. Currently, with lots of professionals jumping to join project management field, there is more to it like resultant project failures and funds running down the drain. Identification and pin-pointing of exact problem orientation in the emerging field of study may be clouded by these speculative theories and concepts that may not be academically proper.

\section{MAJOR QUESTION}

Does proper academic and professional project management qualification contribute significantly to the failure and or success of projects in Africa?

\section{OTHER QUESTIONS}

To what extent does the current certification contribute to the damage to the profession of project management?

To what extent does the current certification processes contribute to the failure of projects?

Can proper academic and professional qualifications improve project success?

\section{OBJECTIVES}

The major objectives of this paper are:

$>$ To clarify the importance of proper academic and professional project management qualification to the field of project management in Africa

To highlight major problem areas associated with project failures in Africa

To prove to what extend proper academic and professional project management qualifications positively influence project success.

To highlight the importance of proper academic and professional project management qualification as a field of study in Africa.

\section{LIMITATIONS OF THE PAPER}

The scope of the paper was too big and limitations were on the availability of resource materials to read and analyse for this paper.

Availability of reliable documentary analysis in terms of research material providing accurate current information was also another limiting factor

\section{RELATED LITERATURE}

Marnewick (2014) argues that, whilst it is agreeable that project management is an emerging field of study, it also goes on to say that most if not all of our practitioners in Africa lack formal education or training on project management. Rwelamila (2012) argues that Management assigns individuals as Project Managers with expectations of high performance yet knowing that they do not have proper academic and professional qualifications comparable to what they themselves academically and professionally attained.

Mounir's (2013) argument that Executives and Senior Managers are employed based on academic and or professional qualifications which if equated would be a Bachelor's Degree in Management (3/4 Years) and or an Msc or MBA (1/2 Years) in Management. The same level of appointment is accorded a Project Manager who holds a PMP certification of at maximum (6 Months) otherwise a five (5) day course in Project Management. 


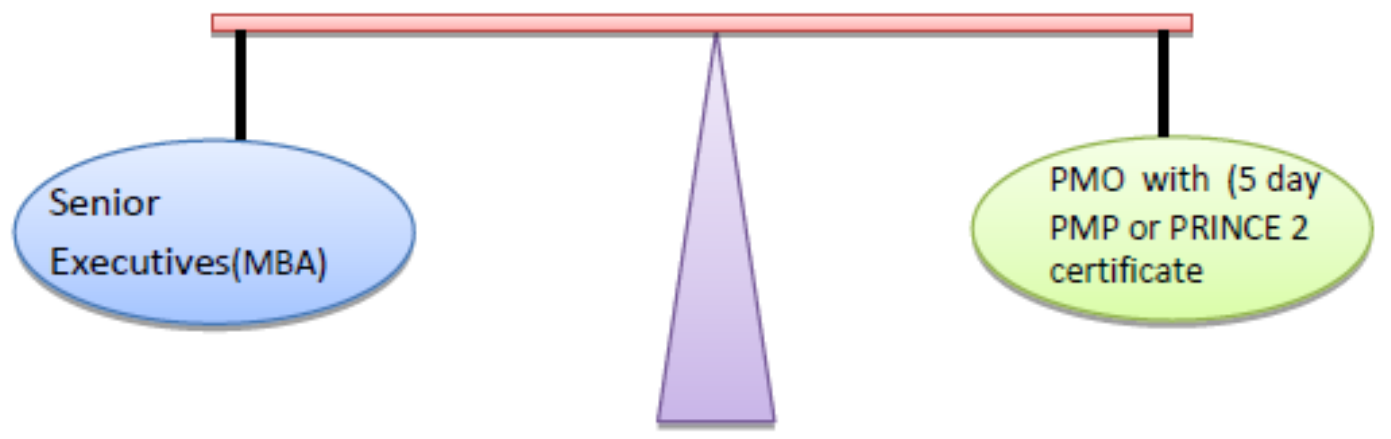

Fig1. Scale showing how Project Managers are equated with Senior Executive Managers

Many critics would try and analyze why a situation like this exist as diagrammatically shown above. The argument would be that because project management is easy it could be easily understood within 5 days or that Project Managers are Technical people from other fields who are briefly oriented to a simple field of project management for a few days and then they are as good as actual academics and or professionals in the field.

According to Gardiner (2005) this is not reflected in the outcome of the projects implemented by these Project Managers. Definitively project failure is the result in many instances. Despite meeting Senior Executive set objectives and expectations, an overall analysis shows disparities and hence project failure. This mode of project management is labeled appeasement management, whereby expected objectives are strived to be met without looking at the overall objectives or principles of project management.

\section{THEORETICAL FRAMEWORK}

In his Project Management Trilogy Challenges in Africa, Rwelamila (2012) points out that the current project management training if falling short of fundamental knowledge areas. It is arguably true therefore that when Graham and Englund (2004) emphasizes that projects are the highways of economic and social development but strongly hinged on the environmental accommodation more than the capabilities and proper academic and professional qualifications of the project manager himself.

Prof, Marwick (2014) argues that with all practical guidelines from short courses being offered, there is still a gap and an allowance of failure and practically projects have been failing. The causes of this, he attributed to the simple fact that Project Managers lives a lot to be desired. That is, theoretically there is still more learning and education to be endowed to project managers than a mere five (5) day course.

Mounir (2014) went on further to highlight the fact that theoretically millions of dollars are entrusted to these shortterm trained project managers and the money is lost down the drain.

In Africa, there has not yet been a university offering a Bachelor's Degree in Project Management. There are several training institutes offering Project Management Professional courses, PMI, PMP, Princelletc yet there is not even a single academic institute offering degrees in project management.

Statistically, a few Universities in the world are offering this domain on its own. In most cases, project management is being offered as an elective course strengthening other fields of study. It is seldom offered on its own especially

\section{Project Management Academic Qualification in Africa}

Research has shown and proved that project management in Africa is still an area of persistent pains. In South Africa, a research by professor Marnewick (2014) showed that there is more project failures than success. This seems to be inherent from all other parts of the world where project failures are prevalent than success.

Arguably, the rate of project management academic qualifications at institutes of higher education in Africa are directly inversely proportional to project failures in any country. However in some African countries, where project management has been institutionalized and taken as field of major domain, the rate of project success is witnessed to be improving than those countries where project management is still a long way to be institutionalized. 


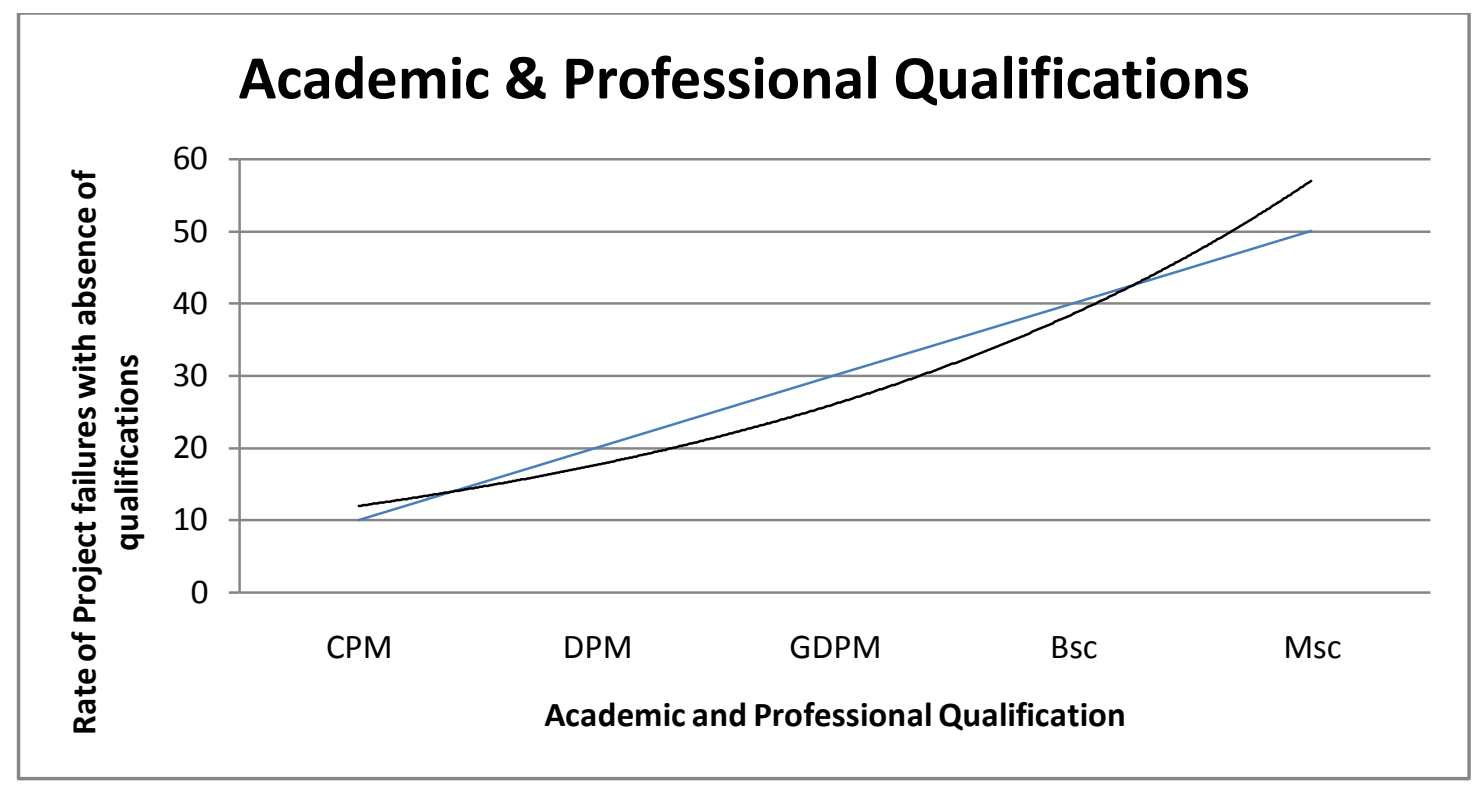

Graph showing exponential inverse proportion of the presence of project management academic and professional qualifications and rates of project failures.

The argument is that project management has been witnessed as being instrumental in organizational success due to introduction of projects. However, such organizations which use project management as an objective achievement tool, have witnessed meeting of their objectives and hence project success and thus organizational success. However, such organizations which entirely rely on General management technics, are finding themselves in murky waters and thus the absence of project management results to derailed success if any but rather project failure and or organizational failure.

In South Africa, for example, even though, the country curriculum has not yet embraced the field of project management in institutions of higher learning except at higher levels of qualifications, the recognition of the field is encouragingly increasing and hence efforts for project success is being witnessed.

Looking at other neighbouring African countries to South Africa, you will find that very few countries offer project management academically at institutes of higher education. In Botswana, Swaziland, Lesotho, Mozambique, Zimbabwe, Zambia, Malawi, Tanzania etc, there is no university offering project management as an academic domain.

Still in South Africa, it is only a number of universities such as Stellenbosch, UNISA, University of Pretoria and Cranefield College which are offering project management and all of them does not offer a Bachelors Degree Programme for that matter.

It is in Zimbabwe that efforts are being made to engage the government to include project management in the curriculum of education at higher institutes of learning like Technical Colleges (Polytechnics), Colleges and Universities. Great Zimbabwe University, has taken some strides in offering the entire project management professional courses as well as academic courses. They intend to offer a Bachelor of Science Degree in Project Management and a Master of Science in Project Management in collaboration with The Project Management Zimbabwe. In Botswana, Cranefield College is introducing its programmes to crack open the project management sealed domain in that country.

\section{Project Management Short-Term CourSeS}

The argument that project management as a domain is not difficult and hence is simple does not hold any water. If project management is simple, then why experience project failures from personnel trained in short-term courses. Short-term courses implies that the entirety of a programme can be understood within a short period of time, thus implying simplicity. 


\section{American Research Journal of Business and Management, Volume 1, Issue 1, February 2015 ISSN 2379-1047}

It is very unfortunate that other fields of study do not have such preferential treatment in terms of training. You can rarely find a person doing an Engineering Programme within 5 days or an Accounting Programme over 3 days. Yet project management is being run on 2-5 days even at University level.

The perception that project management is simple has led to Senior Executives opting for PMOs for a specific objective to be met, if met, then project management is a success but if not, either way, the PMO is dumped and other alternatives sought. That makes project management an experimental management tool by Senior Executives, it is never a permanent option. Thus, the reason why most training is short-term and not industry specific.

\section{XiI. Project Management "A Myth"}

In reality, project management is a field of study that is still mysterious even to the most professionals who confess to know it. Most often a project management professional profess knowledge with referral to part of project management for example, Scheduling, WBS, etc, which are far from the domain of the field of study in project management.

Worse still, when overemphasized project management courses like PMP or PMI or PRINCE 2 are expected to turn people into expert over 5 days or 3 months. These heavy badges of these short-courses has led to big organizations, governmental and non-governmental to trust such shot-term experts with millions of dollars and expect miracles to turn around their organizations into success stories.

In some high profile meetings, you will find project management experts discussing wrong topics of project management resting assumptions on the fact that they all know what project management is. To drill these individual experts on what exactly project management is, that's when you will find a different definition of an elephant from different blind people.

However, limitations to accord proper project management academic and professional qualifications is the extent to which these short courses have been acquired and how they have been used as proper academic qualifications. To revert to proper academic and professional qualifications would mean disqualifying to some extent these qualifications which many would not agree with you. Currently, there are huge projects and organizations being run by PMOs with only PMP as a qualification attained in 5 days or weeks. The resistance coming from such areas is fierce.

\section{CONCLUSION}

Major professional certification in project management which goes without much to say in terms of contributing to the domain of this field of study is the Project Management Professional (PMP), IPMA, PRINCE2 and many others yet academically there has not been much development along certification. These certifications have been very instrumental in becoming catalyst of professional transfers from technical domains to project management.

Such has been a tendency that these certifications have been used as "one size fits all", whereby application has been to all fields like Construction and in Engineering or Information Technology. The demise of using "The Project Management Bible" called the PMBOK disregard the fact that it is nothing but a generic standard which is supposed to be used by other standards for specific fields.

This paper tries to highlight the point that there are a lot of shortfalls being presented by professional qualifications to an extend that many people confuse certification with project management. It has been this paper's thrive to clarify that proper academic and professional qualifications can do a lot in reducing project failures and clarifies on lots of cloudy areas in project management as a domain in Africa.

Conferences or Forums like this should materialize tangible results in academic and professional project management certification implementation across Africa. Let us get Project management Experts to work on this project and see how successful they can be.

\section{RECOMMENDATIONS}

\section{The following recommendations are essential}

$>$ More studies need to be conducted in this field of project management

$>$ Project Management should be uncalculated in the curriculum of African countries at Higher levels of education

$>$ There should be a holistic approach to implementation of project management academic and professional qualifications in Africa 
$>$ The discussions on project management conscientisation in Africa should be separately be looked at from business expansions in Africa

$>$ An African Project Management Committee of Experts should be formed to oversee the implementation of project management domain in Africa and to oversee the operations of Project Management Associations in various countries.

$>$ Dialogue should be opened amongst Project Management Association in different countries to enable sharing of researches and academic activities in different countries

\section{REFERENCES}

[1] Fischer, D. (2013) Project Management. New Hampshire: Plymouth State University.

[2] Gardiner, P.D. (2005) Project Management: A Strategic planning approach. New york: MacMillan.

[3] Graham, R.J. and Englund, R.I. (2004) Creating an environment for successful projects.San Francisco, Jossey-Bass.

[4] Harris, P.E. (2014) Techniques for Managing Complex Projects. Victoria: Eastwood Harris (Pvt)Ltd.

[5] International Project Management Association (2007) International competence baseline.The Netherlands.

[6] Marnewick, C. (2014) Take an Information Technology Project Audit. Johannesburg: PMSA Knowledge Series

[7] Meyer, W. (2013) Understanding Decision Behaviour in Failing Projects. Lille: SKEMA Business School.

[8] Mounir, A.A. (2013) Managing Projects: Challenges and Methods. Bookboon.com

[9] Project management Institute (2013) A guide to the project management body of knowledge (PMBOK) Newton Square: Project Management institute.

[10] Rwelamila, P.D. (2012) Project Management Trilogy Challenges in Africa - Where to from here? Project Management Journal Vol, 43 No. 4 5-13, Wiley Online Library.

[11] A Guide to the Project Management for Development Professionals (PMD PRO1) (2010) 